\title{
Wireless Internet Technology to Support Learning in the University of Jordan: Students Voices
}

\author{
http://dx.doi.org/10.3991/ijim.v9i3.4031 \\ Mansour Alwraikat \\ The University of Jordan, Amman, Jordan
}

\begin{abstract}
The aim of this study is to determine the obstacles that students face at The University of Jordan when using wireless Internet technology. In addition, the aim of this study is to determine any statistically significant differences in student perceptions of the obstacles faced when employing wireless Internet technology regarding their gender and university educational level. A stratified sample of (500) students (male, female) was selected from the University of Jordan during the 2013-2014 academic year. A questionnaire with three sections was developed to collect data to answer the research questions of the study. The first section compiled demographic information; the second section consisted of (11) items, and third section consisted of an open-ended question. Results showed that student perceptions of the obstacles they encountered during their use of wireless Internet technology in learning were exceedingly high. There were also statistically significant differences among student perceptions concerning the obstacles related to the utilization of wireless technology with regard to gender (females). Nevertheless, there were no statistical significant differences with the means of student perceptions concerning the obstacles related to exploiting wireless technology at the university-level educational experience. The main obstacles faced by the students included the poor Internet wireless coverage in an important number of buildings in the University of Jordan and lack of sufficient power switches to charge portable devices on campus.
\end{abstract}

Index Terms-Wireless Internet, Obstacles, Students, Learning, The University of Jordan.

\section{INTRODUCTION}

Wireless communications technology has witnessed a tremendous technical leap, which imposed itself strongly on all sectors of society, including the educational sector, in recent years. There is no doubt that this technology is playing multiple roles and affecting everything in our daily lives, as reliance on wireless Internet connectivity continues to grow.

Enthusiasts of educational technology believe that the use of wireless communications technology will lead to increasing the effectiveness and efficiency of the education system and allow free access to sources of educational material, as well as mitigate the shortage of scientifically and educationally qualified faculty members, all the while considering individual differences and overcoming various educational problems. Importantly, it also provokes interest and satisfies the needs of students to learn and increase their participation in the educational process [1].

With the development of technology, the evolution of educational thought and their efforts to create new learning environments, states seek to introduce the latest technology to facilitate learning and satisfy student needs to learn, communicate and work. In addition, educators seek to make the learning environment accessible and flexible to everyone so that students can access information and study from any place at any time, to help enhance their knowledge and skills, to address individual differences among them, and manage anywhere and anytime learning, as well as adapt to their abilities and learning styles, to support individual learning, distance learning, and lifelong learning [2].

Wireless technology represents one of the most important advances to make inroads into most people's lives; it is growing and spreading dramatically in colleges, universities, schools, homes, shops and shopping centers. Persons from all over the world presently use the Internet for various reasons including e-mail, online sharing, online shopping, research, games, and learning. In short, despite any inconveniences, wireless technology has become extremely important in the lives of learners, especially with the advent of mobile devices and laptops equipped with long-term batteries, which use wireless Internet service without the need for cable connections [3].

\section{A. Obstacles of Using Wireless Internet Technology in Learning}

The properties enjoyed by employing the wireless Internet in learning promise boundless benefits of enormous importance to the learner, however, several challenges and obstacles exist that hinder its utilization, including its novelty, its rapid and continuous updating, and its expansion into so many new realms. Exploring a number of issues and challenges facing wireless Internet and mobile wireless devices preceding the adoption and exploitation of this technology is extremely vital to unfold the barriers that hinder its development. Despite the proliferation of wireless Internet services on a wide scale, the increasing number of simultaneous users reduces its speed and their lower degree of protection than wired Internet services are of great concern. Moreover, the social, cultural, and institutional barriers facing the implementation of wireless technology is also a concern, with privacy protection and security of wireless networks being of greatest importance [4]. Many educators have voiced their concerns about 
using wireless Internet service in learning. The following procides some of their concerns:

- Distraction: Wireless technology may disrupt learning activities as some students spend valuable times with their mobile devices exploring social web pages such as Facebook, Twitter, YouTube and Google [3].

- Bandwidth: Bandwidth is a source of concern for institutions and individuals because wireless systems typically operate over distances ranging from 100 to 500 feet, and wireless local area networks are more effective when they are within this range. Existing systems primarily utilize radio frequency waves, which can penetrate walls and ceilings [5]. Nevertheless, [6] bandwidth in wireless LANs is limited compared to traditional wired LANs.

- Risk protection and technical challenges: People may expose wireless local networks to unauthorized access from outside the network. These individuals may exploit a resource-based network, including access to the Internet, fax servers, and disk storage. Furthermore, the network can be exposed to different types of attacks that could crash the entire network, could lead to denial of wireless service to the network and to obtaining services without license or authorization and exposure to legal liabilities. A wireless LAN's signals may exceed the intended space and seep from the ground or the limits of construction, becoming prey to a piracy "attack, or allowing individuals to decrypt codes and gain access to wireless data [7].

- Exposure to wireless devices: It is believed that if the password that protects the wireless network is identified, hackers may have access to personal information and steal it [3]. Various laptops come with built-in Wi-Fi capabilities, which are less secure than wired connections (such as Ethernet) since hackers do not need a physical connection. This signifies the adoption of different Wi-Fi encryption techniques; however, it is relatively simple to penetrate WEP encryption. Thus, high-quality protocols (WPA, WPA2) have to be added to provide greater security. With the advent of an optional feature called Wi-Fi Protected Setup (WPS), the Wi-Fi Alliance updates its test plan and certification programs to ensure resistance to almost all modern hardware-based attacks [7].

- Blocking or signal interference: The most common is the blocking of signals due to walls, columns, and other obstructions which can reduce the strength of wireless signals, which severely limits the existing contact in a wireless local area network. Furthermore, the existence of a group of wireless devices in close proximity may cause interference in radio frequencies. Furthermore, wireless LANs require what is referred to as "line of sight", which is hard to secure in crowded areas. In addition, unlike with Ethernet cables, wireless networks have futile points that can significantly limit the speed of communication, since the weather can play a major role in weakening the contact [5].

- Slowing of wireless network speeds: Although wired networks are faster than wireless networks to some extent, the difference between them is the speed of Internet connection; however, the speed of wireless Internet becomes slower as the number of users increases [4].

- Cost: Implementation of wireless systems is relatively expensive, especially for small projects. However, after installing the network, the cost of each system access point diminishes. Therefore, costs will continue to decline as the number of users increases [5]. For many, wireless technologies are still far from being effectively utilized in learning. Therefore, officials, teachers, and students need to be seriously engaged to determine how to employ modern techniques to achieve educational goals, rather than on the acquisition of latest technology without considering its effective exploitation and integration in learning [4].

\section{B. Problem Statement and Research Questions}

The goal of this study is to identify the primary obstacles facing students at the University of Jordan in their utilization of wireless Internet technology in learning. In addition, this study seeks to emphasize whether these obstacles are associated with variables such as gender and academic level. The decision to select these variables came after reviewing the literature and previous studies in which these variables were shown they might contribute to the matter being observed. Therefore, the core of the research problem lies in answering the following questions:

- What are the estimates of University of Jordan students regarding the obstacles that hinder the use of wireless Internet technology in their learning?

- Are there any statistical significant differences in the students' estimates of the obstacles that hinder their use of wireless Internet in learning due to their gender and University academic level?

- What suggestions can be offered to overcome these obstacles and to activate greater use of wireless Internet technology in learning within the university?

\section{Procedural Definitions}

Wireless Internet Technology: Is a mean used by the students in their learning to access Internet services through connections via their computers, mobile phones, and portable digital devices to enable them to connect to the Internet anytime and anywhere with the University of Jordan.

Obstacles: The issues that prevent and limit the students' use of wireless Internet technology in the University of Jordan from achieving their learning goals, as measured by student responses graded on a scale.

\section{Significance of the Study}

Despite the fact that wireless technologies can offer plentiful benefits in learning and teaching, there is a lack of academic studies and scientific research which examine the obstacles that may hinder the utilization of wireless technology in learning. This study first examines the obstacles to use by students at the University of Jordan by shedding light on its impact on student learning within the campus for the sake of helping officials in the university to overcome these hindrances. Due to the scarcity of studies within this field in the Arab countries, this study may represent a contribution to Arabian study on this topic.

\section{E. Purpose of the Study}

The increasing use of wireless Internet on its campus will turn The University of Jordan into a huge laboratory, which will permit all to benefit from the advantages of the Internet and its easy and free services, as well as take advantage of the potential of this technology in learning. Therefore, the impact of this technology on student learning is worthy enough to conduct this study in the university since wireless Internet technology service is supplied 
PAPER

WIRELESS INTERNET TECHNOLOGY TO SUPPORT LEARNING IN THE UNIVERSITY OF JORDAN: STUDENTS VOICES

free of charge to students, faculty, administrative personnel and visitors to The University of Jordan, where it is available in several of the university's buildings.

\section{LITERATURE REVIEW}

Although the implementation of wireless educational technology is spreading very quickly, there are still relatively few studies that adequately report its effects. A review of previous work in the Arabic language shows a lack of studies that examine the employment of wireless Internet in educational and learning processes, specifically in Jordan, despite its rapid spread. In addition, a review of the literature shows a lack of studies that address the problem of the study directly, since most of the previous studies tackle the utilization of the Internet in general, while, other studies address wireless Internet in terms of scientific, technical, and technological aspects only. Below is a presentation of some of those studies:

[8] highlights the need to adapt wireless technologies by educators and students. He states that "The most challenging problem facing higher education systems incorporating wireless devices into their classrooms is technical support" (p. 38). He believes that several campuses lack the resources to provide their faculty and students with essential tools to utilize emerging technologies in reasonable ways. In addition, one of the challenges that affect the fullest potential of wireless technology in classrooms is electromagnetic interference and physical obstacles that limit coverage of wireless networks.

[9] report in their study that almost five of the universities that have implemented a wireless technology service have complained of its use for non-academic purposes by students during academic meetings in classrooms.

[10] used an online questionnaire, interviews and personal visits, and case studies with a group of undergraduate and graduates students in a number of public and private colleges and universities in the United States as a tool to examine the problems and solutions related to wireless networks in different institutions, and gather information needed to answer key questions for wireless networks: Where are we now? And where we are heading? And what have we learned? The results showed that the criteria for wireless networks are still a challenge, especially when it comes to security and the protection of wireless networks.

[11] surveyed the opinion of 392 members of the organization EDUCAUSE via the Internet to create a wireless network in higher education and understanding of the characteristics of implementation, also they conducted interviews with 17 specialists in information technology who have a role in the implement of wireless network or who use the wireless Internet, and they applied case studies in some universities in the United States. The results tackled some challenges associated with wireless networks and the compatibility of wireless network with the expected solutions. Inappropriate use of a wireless network in the classroom requires asset of rules for acceptable utilization of wireless technology in and outside the classroom. Also, security issues typically related to effective authentication and authorization procedures were addressed. In addition, the need to support students using a variety of wireless connections in different ways proved to be a challenge.
[12] reports that security and end-user support were the main challenges that hinder the use of wireless networks. In addition, other challenges were manifested in the ability for supporting printing, and exchange data with the wired network.

[13] Believes that allowing access for laptops from outside the school on the network intensifies the threat of spreading computer viruses and hacker attacks. Also, Trotter points out that the radio spectrum used by all of the " $b$ " and "g" versions can be intercepted and infiltrated by mobile phones and microwaves, and other devices. In addition, speed plays a crucial aspect when there are several students competing to login onto the same website and bandwidth is not sufficient. At the university level, ownership of PC by every student to accommodate wireless Internet devices represents a great setback to not utilizing this technology with its fullest potential.

After reviewing previous studies, we noted the results of these studies indicated the importance of using wireless Internet for students. Also, a good number of educational institutions have turned to the use of wireless networks or have planned to shift to wireless networks. Wireless networks are becoming an essential complement to educational institutions because of their importance and effectiveness in the learning process. In addition, results indicated that the majority of students have positive attitudes toward wireless networks. Moreover, wireless services being used to encourage learning centered on the learner provides for mobile learning, thus enhancing the learning environment, and facilitating collaborative work, participation and communication among learners. Finally, studies have shown that laptops are principally employed to access wireless services. Hence, this role needs more attention and support to more fully utilize wireless Internet for educational purposes reconsidering the necessary infrastructure; by using and integrating it into learning to achieve the desired objectives.

\section{METHODOLOGY}

Researching related problems in human fields requires a description of the problem we want to study. Furthermore, we need to collect feasible descriptions and accurate information. After the researcher identified the problem of the study, reviewed previous studies and various research approaches, he determined that the most appropriate design for the study is the descriptive approach, which involves using a survey for gathering information for scientific purposes from a sample of a population because it provides the researcher with data and information that may contribute significantly to the description and interpretation of the data, which helps better understand the phenomenon.

\section{A. Sample of the Study}

A stratified random sample was selected consisting of (450) undergraduate students and (50) graduates from the scientific colleges in the University of Jordan during the second semester of the academic year 2013/2014. The idea behind choosing scientific colleges rather than humanities colleges was that, since this study will be the first of its kind in the university on this level, it is extremely important to include the target population resembled by first-hand users in scientific colleges. Only (403) undergraduate and (45) graduates returned the questionnaire, (179) were male, and (269) were female. 


\section{B. Instrument of the Study}

For the sake of answering the research questions of the study, the researcher developed a self-administered questionnaire after reviewing the literature related to the subject, centering wireless Internet, and has taken advantage of the theoretical framework of this study which has benefited from work by [4], [3], [10], [11] and [14] to construct the items of the questionnaire. The questionnaire consisted of three main sections: first one, covered demographic information; the second consisted of 11 items with closeended questions related to the obstacles facing students using wireless Internet technology; and the third section was an open-ended question to offer the participants the opportunity to share their own comments and opinions regarding the suggestions to activate the use and better benefit from wireless Internet technology in learning. A five-point Likert scale was used (very great, great, moderate, weak, very weak), so that (5) was given to very great, (4) to great, (3) to moderate, (2) to weak, and (1) to very weak.

\section{Validity of the Study}

Face validity was ensured by ensuring that the questionnaire actually measured what it was intended to measure. The items were phrased appropriately, and the options for responding seem allowed for distancing the responses. This was accomplished by submitting the questionnaire to a group of eight experts from faculty members in curriculum and instruction, measurement, and educational technology. Additionally, to attain content validity, the experts were asked to judge the appropriateness of phrases of the scale used in the questionnaire in terms of its comprehensiveness, clarity, and language. They were asked to change, delete, and add anything to the items of the scale that might help insure its validity. Thus, the researcher considered the views of experts and their amendments in relation to the items of the scale significant enough and sincere for conducting the study.

\section{Reliability of the Study}

Testing and re-testing was used to check the reliability of the instrument of the study. The test and retest assesses the degree to which test scores are consistent from one test administration to the next. Therefore, the researcher distributed the instrument among 20 students from outside the sample of the study, and re-applied the questionnaire with the same group of students after two weeks and then the reliability coefficient was extracted by calculating Pearson correlation coefficient between the first and second application, where the reliability coefficient was (0.83), which is suitable for conducting the study.

\section{E. Variables of the Study}

The independent variables were gender, with two levels (male, female), and university academic level, with two levels (undergraduate, graduate). While the dependent variable was student estimates on the scale used to measure the significance of obstacles when using wireless Internet technology in learning.

\section{RESUlTS}

To determine the student estimates of the obstacles that hinder the use of wireless Internet technology in their learning at the University of Jordan, means, standard de- viations and ranks of the student estimates of obstacles they face when using wireless Internet in learning were calculated, as illustrated in table I.

Table I shows that the means scores of the obstacles faced by students at the University of Jordan for wireless Internet in learning ranges from (3.31 to 4.12), and obstacles that occupy the ranks of 1-9 receive the highest marks, of which, the top three are:

1. Limited coverage of wireless Internet technology inside all buildings and facilities in the University of Jordan.

2. The lack of coverage of all the University of Jordan with wireless Internet technology.

3. Lack of sufficient power switches for charging portable devices on campus.

While obstacles that occupy the ranks of 10 and 11 received the lowest means scores (3.31 to 3.37), which are:

10. Wireless Internet interruption during the information search.

11. Wireless Internet lines are being busy in a regular basis.

TABLE I.

MEANS AND STANDARD DEVIATIONS AND RANKS IN DESCENDING ORDER TO THE STUDENT'S ESTIMATES OF OBSTACLES

\begin{tabular}{|c|c|c|c|c|c|}
\hline No. & Rank & Item & Mean & St. D & Degree \\
\hline 7 & 1 & $\begin{array}{l}\text { Limited coverage of wire- } \\
\text { less Internet technology } \\
\text { inside all buildings and } \\
\text { facilities in the University }\end{array}$ & 4.12 & 0.99 & great \\
\hline 8 & 2 & $\begin{array}{l}\text { The lack of coverage of all } \\
\text { the University of Jordan } \\
\text { with wireless Internet } \\
\text { technology }\end{array}$ & 4.04 & 1.01 & great \\
\hline 10 & 3 & $\begin{array}{l}\text { Lack of sufficient power } \\
\text { switches for charging } \\
\text { portable devices on campus }\end{array}$ & 3.78 & 1.20 & great \\
\hline 1 & 4 & $\begin{array}{l}\text { Unavailability of portable } \\
\text { devices to support the } \\
\text { learner access to the Inter- } \\
\text { net }\end{array}$ & 3.76 & 0.86 & great \\
\hline 6 & 5 & $\begin{array}{l}\text { Blocked access to many } \\
\text { educational and communi- } \\
\text { cative sites inside the } \\
\text { University }\end{array}$ & 3.76 & 1.18 & great \\
\hline 3 & 6 & $\begin{array}{l}\text { Slow in Internet wireless } \\
\text { network }\end{array}$ & 3.67 & 0.95 & great \\
\hline 11 & 7 & $\begin{array}{l}\text { Fear of piracy for infor- } \\
\text { mation on mobile device } \\
\text { when using the wireless } \\
\text { Internet on campus }\end{array}$ & 3.67 & 1.18 & great \\
\hline 2 & 8 & \begin{tabular}{|l|} 
Frequent breakdowns in \\
Internet Wireless network \\
\end{tabular} & 3.59 & 0.92 & great \\
\hline 9 & 9 & $\begin{array}{l}\text { There are times (as holi- } \\
\text { days), for example, where } \\
\text { the Internet wireless service } \\
\text { is not available }\end{array}$ & 3.53 & 1.04 & great \\
\hline 4 & 10 & $\begin{array}{l}\text { Wireless Internet interrup- } \\
\text { tion during the search in the } \\
\text { information and communi- } \\
\text { cation network }\end{array}$ & 3.37 & 1.02 & moderate \\
\hline \multirow[t]{2}{*}{5} & 11 & $\begin{array}{l}\text { Wireless Internet lines are } \\
\text { being busy in a regular } \\
\text { basis }\end{array}$ & 3.31 & 1.00 & moderate \\
\hline & & Total Degree & 3.69 & 0.95 & great \\
\hline
\end{tabular}


We noted that the mean score of student responses in the University of Jordan on the scale of obstacles dissuading the use of wireless Internet technology in learning as a whole was high (3.69).

The second research question is: "Are there any statistically significant differences in the students' estimates of the obstacles that hinder their use of wireless Internet in learning due to their gender, and university academic level"? To examine this, an independent sample t-test was performed to examine the significance of any differences of the estimates of obstacles in means scores for students with regard to their gender and university academic level, as illustrated in tables II and III.

Table II indicates that there are no statistical significant differences at the level of $(\alpha \leq 0.05)$ due to student gender insofar as their estimates of the obstacles they face when using wireless Internet technology in learning. The $t$ value was $(-1,508)$ and its level of significance was $(0.132)$, which is not a statistically significant value at a level of $(\alpha$ $\leq 0.05)$; the mean scores for males was (3.61), and for females was (3.75).

Table III shows that there are no statistical significant differences at the level of $(\alpha \leq 0.05)$ due to students' university academic level insofar as their estimates of the obstacles they face when using wireless Internet technology in learning. The calculated t value was (0.638) and its level of significant was $(0.524)$, which is not statistically significant at the level of $(\alpha \leq 0.05)$. The mean scores for undergraduate students were (3.70) and (3.61) for undergraduate and graduate students, respectively.

To answer the third research question regarding suggestions about how to overcome these obstacles and promote a greater use of wireless Internet technology in learning within the university, student responses on the third section of the instrument of the study were collected and classified according to student gender and student university academic level. Table IV shows the distribution of responses of the sample of the study.

As illustrated in table IV, 250 students answering question 3 represent the total sample of the study, or $56 \%$ of the students. The number of males of the study sample who responded to the question was 85 with $19 \%$ of the responses, where 165 females responded, which represents $37 \%$ of the responses. The number of undergraduate students from the sample of the study who responded to the question was 225 , representing $50 \%$ of the sample of the study, while the number of graduate students was 25 , or $6 \%$ of the sample of the study. Student answers ranged from 20 to 80 words which have been classified according to their frequency and importance from the viewpoint of the students, as shown in table $\mathrm{V}$.

Table $\mathrm{V}$ shows that the suggestions that received the highest percentage were respectively:

1) expanding access to wireless Internet in all colleges of the university by $(15.2 \%)$.

2) increasing spaces for tables and chairs to accommodate larger numbers of students by $(9.8 \%)$.

3 ) increasing the number of power switches in the reading halls and electrical connections and repairing damaged ones to use in operating and recharging students portable devices by $(9.8 \%)$.

4. allowing students to access the educational video sites such as YouTube by $(8.9 \%)$.
TABLE II.

RESULTS OF T-TEST FOR STUDENTS WITH REGARD TO THEIR GENDER

\begin{tabular}{|l|c|c|c|c|c|}
\hline Gender & Number & Means & St.D & t & Sig. \\
\hline Male & 179 & 3.61 & 1.02 & $-1,508$ & 0.132 \\
\hline Female & 269 & 3.75 & 0.90 & & \\
\hline
\end{tabular}

* Significant at the level of $(\alpha \leq 0.05)$

TABLE III.

RESULTS OF T-TEST FOR STUDENTS WITH REGARD TO THEIR UNIVERSITY ACADEMIC LEVEL

\begin{tabular}{|l|c|c|c|c|c|}
\hline University academic level & Number & Means & St. D & t & Sig. \\
\hline undergraduate & 403 & 3.70 & 0.97 & 0.638 & 0.524 \\
\hline graduate & 45 & 3.61 & 0.85 & & \\
\hline
\end{tabular}

* Significant at the level of $(\alpha \leq 0.05)$

TABLE IV.

DISTRIBUTIONS OF RESPONSES OF THE SAMPLE WITH REGARD TO THEIR GENDER AND THEIR UNIVERSITY ACADEMIC LEVEL

\begin{tabular}{|l|c|c|c|c|}
\hline \multicolumn{1}{|c|}{ Variable } & Male & Female & Total & Percentage \\
\hline undergraduate & 77 & 148 & 225 & $50 \%$ \\
\hline graduate & 8 & 17 & 25 & $6 \%$ \\
\hline Total & 85 & 165 & 250 & $56 \%$ \\
\hline Percentage & $19 \%$ & $37 \%$ & $56 \%$ & \\
\hline
\end{tabular}

TABLE V.

STUDENTS SUGGESTIONS IN DESCENDING ORDERS FOR THE PERCENTAGE OF THE SAMPLE

\begin{tabular}{|c|c|c|c|}
\hline $\begin{array}{c}\text { Num- } \\
\text { ber }\end{array}$ & Suggestion & \begin{tabular}{|c|} 
Frequen- \\
cy
\end{tabular} & \begin{tabular}{|c} 
Percent- \\
age
\end{tabular} \\
\hline 1 & $\begin{array}{l}\text { Expand access to wireless Internet in all } \\
\text { colleges of the university }\end{array}$ & 68 & $15.2 \%$ \\
\hline 2 & $\begin{array}{l}\text { Increase spaces for tables and chairs to } \\
\text { accommodate larger numbers of students }\end{array}$ & 44 & $9.8 \%$ \\
\hline 3 & $\begin{array}{l}\text { Increase the number of power switches } \\
\text { in the reading halls and electrical con- } \\
\text { nections and repairing of damaged ones } \\
\text { to use in operating and recharging } \\
\text { students portable devices }\end{array}$ & 44 & $9.8 \%$ \\
\hline 4 & $\begin{array}{l}\text { Allow students to access the educational } \\
\text { video sites such as YouTube }\end{array}$ & 40 & $8.9 \%$ \\
\hline 5 & $\begin{array}{l}\text { Increase wireless Internet speed to } \\
\text { facilitate access to information and } \\
\text { communication network to use it in } \\
\text { learning }\end{array}$ & 30 & $6.7 \%$ \\
\hline 6 & $\begin{array}{l}\text { Facilitate the purchase of portable devic- } \\
\text { es for students to activate the wireless } \\
\text { Internet effectively }\end{array}$ & 26 & $5.8 \%$ \\
\hline 7 & $\begin{array}{l}\text { Allow access to social networking sites } \\
\text { like Facebook and Twitter }\end{array}$ & 24 & $5.4 \%$ \\
\hline 8 & $\begin{array}{l}\text { Educate students about available elec- } \\
\text { tronic educational services offered by } \\
\text { the University of Jordan }\end{array}$ & 10 & $2.2 \%$ \\
\hline 9 & $\begin{array}{l}\text { Encourage faculty members to take } \\
\text { advantage of wireless Internet in lectures } \\
\text { and communicating with the students }\end{array}$ & 8 & $1.8 \%$ \\
\hline 10 & $\begin{array}{l}\text { Enable service in classrooms to inte- } \\
\text { grate technology in learning and allow } \\
\text { interaction and communication between } \\
\text { students }\end{array}$ & 8 & $1.8 \%$ \\
\hline 11 & $\begin{array}{l}\text { Enable of service at any time throughout } \\
\text { the academic year }\end{array}$ & 8 & $1.8 \%$ \\
\hline 12 & $\begin{array}{l}\text { Development of wireless local area } \\
\text { networks }\end{array}$ & 6 & $1.3 \%$ \\
\hline
\end{tabular}




\section{Discussion Of The Results}

With respect to the first research question, "What are the estimates of the students in The University of Jordan of the obstacles that hinder the use of wireless Internet technology in their learning", table 1 shows that the means scores of the obstacles faced by students at the University of Jordan for wireless Internet in learning ranges from 3.31 to 4.12 . The mean score of student responses in the University of Jordan on the scale of obstacles for the use of wireless Internet technology in learning as a whole is high (3.69). Therefore, these estimates are in agreement with most of the other studies. This can be explained in terms of the novelty of access into wireless Internet in the educational field in Jordan, the weakness of the necessary infrastructure, the high cost of deployment of the wireless network, and the wireless signal itself, where the signal is weakened by the increasing number of people using it at the same time. In addition, the incremental cost for the ownership of modern technological devices that support wireless communications reduces the ability of students to buy them, especially more so for undergraduate students than graduate students who work at different jobs. Obstacles that ranked 1-9 received the highest estimates; it is worth mentioning that the greatest obstacles according to the responses of students at the University of Jordan was for item 7, which corresponds to "Limited coverage of wireless Internet technology inside all buildings and facilities in the University". It was followed by item 8 which corresponds to "The lack of coverage of all the University of Jordan with wireless Internet technology". This is the case because the coverage of wireless Internet in the University of Jordan is still limited in some of the buildings and is available in only some colleges, especially in those in scientific areas. Despite this weakness in coverage, we noticed that the degree of use was great, so The University of Jordan is seeking to implement a project to cover all buildings and colleges with wireless Internet to overcome these obstacles. This project confirms the lack of sufficient infrastructure in buildings and reading halls at The University of Jordan and substantiates the responses to item 10, the third highest-ranked response, regarding "the lack of sufficient power switches for charging portable devices on campus". While item 1 concerning the "unavailability of portable devices to support the learner access to the Internet" was ranked fourth among the obstacles that students face when attempting to use wireless Internet in their learning activities. This highlights the importance of the availability of modern portable technologies such as laptops, mobile phones, smart and modern digital assistants and other devices, so that students can take advantage of wireless Internet technology in their learning.

Item 6, "Blocked access to many educational and communicative sites inside the University", also represented a significant obstacle as it ranked fifth. This is especially the case of networking sites such as Facebook and Twitter, or video sites, even if they are for educational purposes such as YouTube, which The University of Jordan limits for wireless devices. Item 3, "Slow in Internet wireless network" was considered an obstacle and this is to be expected because the bandwidth of wireless networks is less than wired networks and the increasing number of users on the wireless network at the same time causes this weakness. Item 11, "Fear of piracy for information on mobile device when using the wireless Internet on cam- pus", continues to be among the most significant disadvantages, although significant advances are being made.

Obstacles 10, "Wireless Internet interruption during the search in the information and communication network" and 11, "Wireless Internet lines are being busy in a regular basis" ranked the lowest, with mean scores of 3.31 and 3.37 , respectively. This may be attributed to several reasons, the most important of which is the nature of the wireless Internet, which depends on the frequency of data transmission and wireless devices that can be affected by the surroundings and the possibility of overlapping waves, as well as by the surrounding air and walls. These items which obtained medium estimates can be explained by the fact that wireless Internet is still restricted to a limited number of buildings and a limited number of halls and rooms, and because of poor coverage, which forces students to connect from specific places, such as the main university library, without paying attention to the weakness of the outside contact.

The second research question is whether there are any statistically significant differences in the students' estimates of the obstacles that hinder their use of wireless Internet in learning due to their gender and University academic level. Table 2 indicates that there are no statistical significant differences at the level of $(\alpha \leq 0.05)$ due to student gender in their estimates of the obstacles that face them when using wireless Internet technology in learning. While table 3 showed that there are no statistical significant differences at the level of $(\alpha \leq 0.05)$ due to the student's university academic level in their estimates of the obstacles they face when using wireless Internet technology in learning. The researcher attributes that to the fact that wireless Internet access is available to all students of The University of Jordan, regardless of gender or university academic level; therefore, there are no gender differences in the obstacles faced by the students when they use wireless Internet in learning regarding their gender or university academic level.

The third research question regarded suggestions to overcome obstacles and to activate the use of wireless Internet technology in learning within the university. As shown in table 4, 250 students answered question three representing $56 \%$ of the student responses. Student answers ranged from 20 to 80 words which have been classified according to the percentage of frequency and importance from the viewpoint of the students, as shown in table 5. Data shows that the suggestions which received the highest percentage and represented student requests included:

1. Expanding access to wireless Internet in all colleges of the university $(15.2 \%)$.

2. Increase spaces for tables and chairs to accommodate larger numbers of students $(9.8 \%)$.

3 . Increasing power switches in the reading halls, increasing the overall number of electrical connections and repairing damaged ones to use in operating and recharging students portable devices $(9.8 \%)$.

4. Allowing students to access the educational video sites such as YouTube (8.9\%).

The students' solutions with regards to using wireless Internet in learning closely reflected their point of view about the obstacles they face because the proportion of suggestions reflected the most repeated obstacles they reported in the survey. 
Their suggestions reflect their awareness of the importance of wireless Internet in learning, their ambitions and hopes to improve the wireless network, and develop infrastructure. This confirms that there is currently a lack of equipment prepared for students to help them to learn, and the importance of providing the right environment to take advantage of wireless Internet in learning inside the campus of the University of Jordan. One suggestion which received a considerable response was "facilitating the purchase of portable devices for students to activate the wireless Internet effectively". This may be attributed to the fact that the majority of students are from low wage earners who cannot buy and keep pace with modern technical devices. The suggestion by some students about "Enabling of service in classrooms to integrate technology in learning and allow interaction and communication between students" should be among the actions that must be undertaken by any educational institution to make the learning environment an interactive environment and keep pace with evolving technological advances.

\section{RECOMMENDATIONS}

Based on the findings of the study results, the researchers recommend the following:

1. Implement a wireless Internet project to cover the entire campus of The University of Jordan and all of its facilities, to increase its effectiveness in the learning process, and to expand wireless technology and increase its quality.

2. Develop infrastructure of The University of Jordan and configured to allow the majority of students to take advantage of wireless technology.

3. Spread awareness among students of the importance of wireless Internet access in learning as a step for the possible diffusion of content from inside classrooms and adopt mobile technology in all aspects of the educational process.

\section{REFERENCES}

[1] Shehadeh, A. (2006). Educational technology. Amman: Dar Treasures of knowledge.

[2] Sharples, M. (2000). The design of personal mobile technologies for lifelong learning. Computers and Education Journal, 34 (2000), 177-193. Retrieved on June 07, 2012, from http://www.eee.bham.ac.uk/sharplem/papers/handler\%20comped. pdf. http://dx.doi.org/10.1016/S0360-1315(99)00044-5

[3] Nyakudya, M., N. (2012). Wireless Technology Diffusion within Higher Education Institutions: Determining the Levels of Stu- dent Satisfaction. International Journal of Engineering and Management Sciences, 3(1), 13-23.

[4] Lu, Y. (2006). The Diffusion of Wireless Internet Technology Among University Faculty Members. A dissertation, College of Education at Ohio University.

[5] Yen, D., and Chou, D. (2001).Wireless Communication: the next wave of Internet technology. Technology in Society, 23, 217-226. Retrieved on December 11, 2012 from http://www.journals.elsevier.com/technology-in-society. http://dx.doi.org/10.1016/S0160-791X(01)00010-0

[6] Bansal, R. K., Gupta, V., \&Malhotra, R. (2010). Performance Analysis of Wired and Wireless LAN Using Soft Computing Techniques- A Review. Global Journal of Computer Science and Technology, 10( 8), 67-71.

[7] Turab, N., and Moldoveanu, F. (2009). A Comparison Between Wireless LAN Security Protocols, U.P.B. Sci. Bull., Series C, $71(1), 61-80$.

[8] Oriaku, N. (2008). The challenges and opportunities of wireless technologies in the classroom: related standards and regulations. College Teaching Methods \& Styles Journal, 4(4), 37-44.

[9] Arabasz, P., \& Pirani, J. (2002). Wireless Networking in Higher Education. Retrieved November 02, 2012, from https://www.educase.edu/ecar/.

[10] Boggs, R. (2002). ECAR Study: Communications in Higher Education. Seminars on Academic Computing. Retrieved on March 03, 2012, from http://net.educause.edu/ir/library/pdf/EDU0218.pdf.

[11] Boggs, R., and Arabasz, P. (2002). The Move to Wireless Networking in Higher Education. EDUCAUSE Center for Applied Research,2(7), Retrieved on November 06, 2012, from https://net.educause.edu/ir/library/pdf/ERB0207.pdf.

[12] ECAR Respondent Summary (2002). Wireless networking in Higher Education in the U.S and Canada. Retrieved March 10, 2012, from https://net.educause.edu/ir/library/pdf/.

[13] Trotter, A. (2007). Wireless Technologies Present New Set of Challenges. Education Week: retrieved on March 07, 2012, from http://www.edweek.org/ew/articles/2007/06/20/01sr_management. h01.html.

[14] Lu, Y., Ma, H., and Turner, S. (2004). How Are College Students Using Wireless Internet to Facilitate Learning? Final Report for Wireless Internet Grant Funded by Research Center for Educational Technology, Kent State University. Retrieved on January 25, 2013 from http://www.rcet.org/research/ATT-OLN/Yong-MaTurner-Final.pdf.

\section{AUTHOR}

Dr. Mansour Alwraikat is an Associate Professor in the Educational Technology Program, Curriculum and Instruction Department, College of Educational Sciences at the University of Jordan in Amman-Jordan (E-mail: mansouralwraikat@gmail.com,m.wraikat@ju.edu.jo).

Submitted 11 July 2014. Published as resubmitted by the author 18 June 2015. 